\title{
Improvement of Specific Energy Absorption of Composite Tubular Absorbers using Various Stitching Pattern Designs
}

\author{
A. Rabiee and H. Ghasemnejad ${ }^{1}$ \\ Centre for Structures, Assembly and Intelligent Automation, Cranfield University, \\ MK43 0AL, UK
}

\begin{abstract}
In this paper, various patterns of multi-stitched locations were studied experimentally and numerically to improve the specific energy absorption (SEA) in composite tubular absorbers. In this regard, stitching patterns with a horizontal distance of $3 \mathrm{~mm}, 6 \mathrm{~mm}, 9 \mathrm{~mm}$ and $18 \mathrm{~mm}$ in straight and zig-zag designs were investigated to justify their effect on mean crushing force and energy absorption capability. A multi-shell configuration finite element model is also developed based on energy-based contact definitions, which considers the delamination in Mode-I and stitching pattern design to accurately predict the energy absorption capability and axial crushing behaviour of composite crash absorbers, At stitched locations, the critical normal surface separation was utilised concerning experimental data to improve delamination resistance. The multi-stitching rows of 10-15-20-25-30-35 mm with $3 \mathrm{~mm}$ horizontal and 2.5 $\mathrm{mm}$ vertical distances between each stitched point can increase the specific energy absorption up to $32 \%$ in comparison with non-stitched specimens. The developed numerical model for multi-layered composites absorbers in comparison with the existing methods is efficient in terms of accuracy with less than 5\% error in comparison with experimental data.
\end{abstract}

Keywords: Energy Absorption; Composites; Multi-stitching; Pattern; PARAM

\footnotetext{
${ }^{1}$ Corresponding Author: e-mail: hessam.ghasemnejad@cranfield.ac.uk (Hessam Ghasemnejad), Tel: +44 (0) 1234754395.
} 


\section{Introduction}

In the past two decades, different types of crashworthy components were investigated including various geometrical shapes, material systems and lay-ups, various fabrication methods, trigger mechanism under oblique, axial, quasi-static and impact loading conditions [1-4]. However, the lack of through the thickness reinforcement can be a disadvantage in terms of mechanical performance, low interlaminar fracture toughness, impact damage resistance and crashworthiness behaviour [5]. There are several techniques to improve the mechanical properties and impact damage tolerance in the z-direction or through the thickness, and one of the most cost-effective reinforcing technique is through the thickness stitching, which improves interlaminar strength and delamination resistance [6-8]. It has been shown that stitched reinforcement improves interlaminar fracture toughness and delays delamination crack propagation. Stitched specimens have shown a reduction of delamination within the damaged zone, which indicates an improvement of inelastic stretching of the tested material [9-10].

Liu et al. [11] stated that increase of wall-thickness led to a significant increase in energy absorption, specific energy absorption and peak crush force. In another study, Liu et al. [12] showed that the perforation parameter, significantly affected the crashworthiness of performance of CFRP square tube under axial crushing and the specific energy absorption was found to be sensitive towards a variation in parametric study and perforation parameters. Fu et al. [13] studied the energy absorption characteristics of a bionic-bamboo tube (BBT) under axial crushing. The authors concluded that the energy absorption of BBT was higher than bitubal circular tube, which was attributable to the interactive effect between the ribs and tubal walls.

Warrior et al. [14] investigated the influence of several factors affecting GIC, interlaminar fracture toughness, including, toughened resins, thermoplastic interleaving, thermoplastic resin, and through-thickness stitching using [0/90] NCF, non-crimp fabric GFRP and CoFRM, continuous filament random mat cylindrical tubes. A tougher matrix leads to an increase of $\mathrm{G}_{\mathrm{IC}}$ in composite tubular structures which is an important parameter in the design of crashworthiness [15].

Cauchi Savona et al. [16] studied Mode-I and Mode-II fracture toughness properties using glass/epoxy composite plates. They also [17] investigated the energy absorption capability of 
glass NCFs laminates and stitched carbon laminates subjected to impact loading and showed stitching could potentially improve energy absorption by $30 \%$.

Solaimurugan et al. [18-20] studied axial compression of glass/polyester composite cylindrical shells and parameters affecting SEA, GIC, and progressive crushing such as stacking sequence and through-thickness stitching. The author experimentally showed that a stable crushing process and formation of a higher number of fronds are obtained when axial fibres are closer to the outer surface, with higher energy absorption capability when axial fibres are closer to the inner surface. Moreover, circumferential delamination and stitching are also reported to improve energy absorption.

Ghasemnejad et al. [21] studies hybrid CFRP/GFRP with a layup of $\left[\mathrm{C}_{90} / \mathrm{G}_{0}\right]_{7}$ stitched composite box structures. Delamination studies were carried out by a double cantilever beam (DCB) standard test, and the effect of crack propagation resistance by introducing stitching was studied. The authors concluded that the lay-up sequence has improved SEA value by 5\% and the stitching has significantly improved interlaminar fracture toughness. A similar conclusion was obtained by Zhao et al. [22] and Soloimurugan and velmurugan [20-23].

The multi-layer modelling technique can be utilised for better capturing of the failure process of the tubes undergoing progressive crushing [24-25]. A finite element model developed in [25] accurately predicted the peak load of thin-walled square CFRP tube. Although 33\% of underestimation was observed for specific energy absorption (SEA) value. In [26-27] the Finite Element Model (FEM) was developed and compared with experimental data, the model developed the crushing behaviour of square and hollow circular sections. It was noted that axial matrix splits that contribute to the energy absorption capability of the composite tube were neglected in the model. This resulted in the different collapse modes between numerical and experimental studies, and also different failure mechanism and load-displacement were observed. Several parameters that influenced the crushing behaviour of square hollow tubes were also analysed in [28]. This paper aims to develop experimental and numerical studies to investigate stitching pattern design and its density, which potentially resulted in a $32 \%$ increase in SEA. The developed numerical model for multi-layered composites absorbers in comparison with the existing methods is efficient in terms of accuracy with less than 5\% error in comparison with experimental data. 


\section{Experimental Studies}

This study is in continuation of previous work of the authors [29], which experimentally investigated the relationship of stitching location and SEA capability of glass/epoxy composite tubes. In this research, multi-stitching is achieved by insertion of a needle, penetrating the specimen with Kevlar yarns at specific locations of 10-15-20-25-30-35 mm from the top end of the specimen with $6 \mathrm{~mm}$ spacing (see Figure 1). The crushing response of multi-stitched tubes is analysed by force-displacement graphs and consequently specific energy absorption capability. Tubular absorbers were fabricated by GFRP composite materials (7781/TenCate E772) with a density of $\rho=2250 \mathrm{~kg} / \mathrm{m}^{3}$. A symmetric laminate code of [-45/45/0/90/0/90]S was used with geometry size of $80 \times 80 \mathrm{~mm}^{2}$ using hand lay-up techniques (see Figure 1). The thickness of each ply is $0.25 \mathrm{~mm}$ with a total average thickness of $3 \mathrm{~mm}$ for each specimen.

\section{Stitching locations}

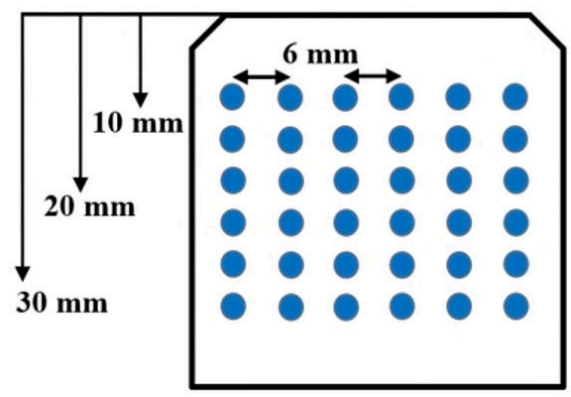

a

\section{GFRP Specimen}

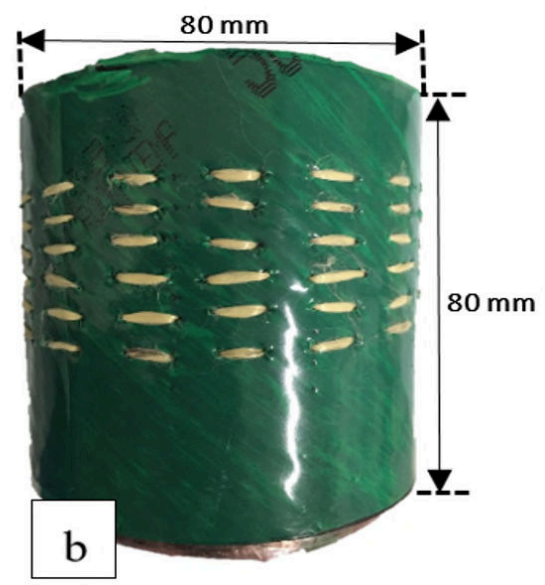

Figure 1. a) Various stitched locations at 10-15-20-25-30-35 mm, b) GFRP stitched specimen (uncured) with a protective layer.

All specimens were tested using a $500 \mathrm{kN}$ load cell capacity hydraulic press under quasi-static loading conditions with a constant velocity of $2 \mathrm{~mm} / \mathrm{second}$ and stroke displacement of $50 \mathrm{~mm}$. The displacement $(\mathrm{mm})$, time $(\mathrm{S})$, and force $(\mathrm{N})$ results were extracted from the test, which results to plot load-displacement graphs for each test. The various crushing process of composite tubes is shown in Figures 2 and 3. 

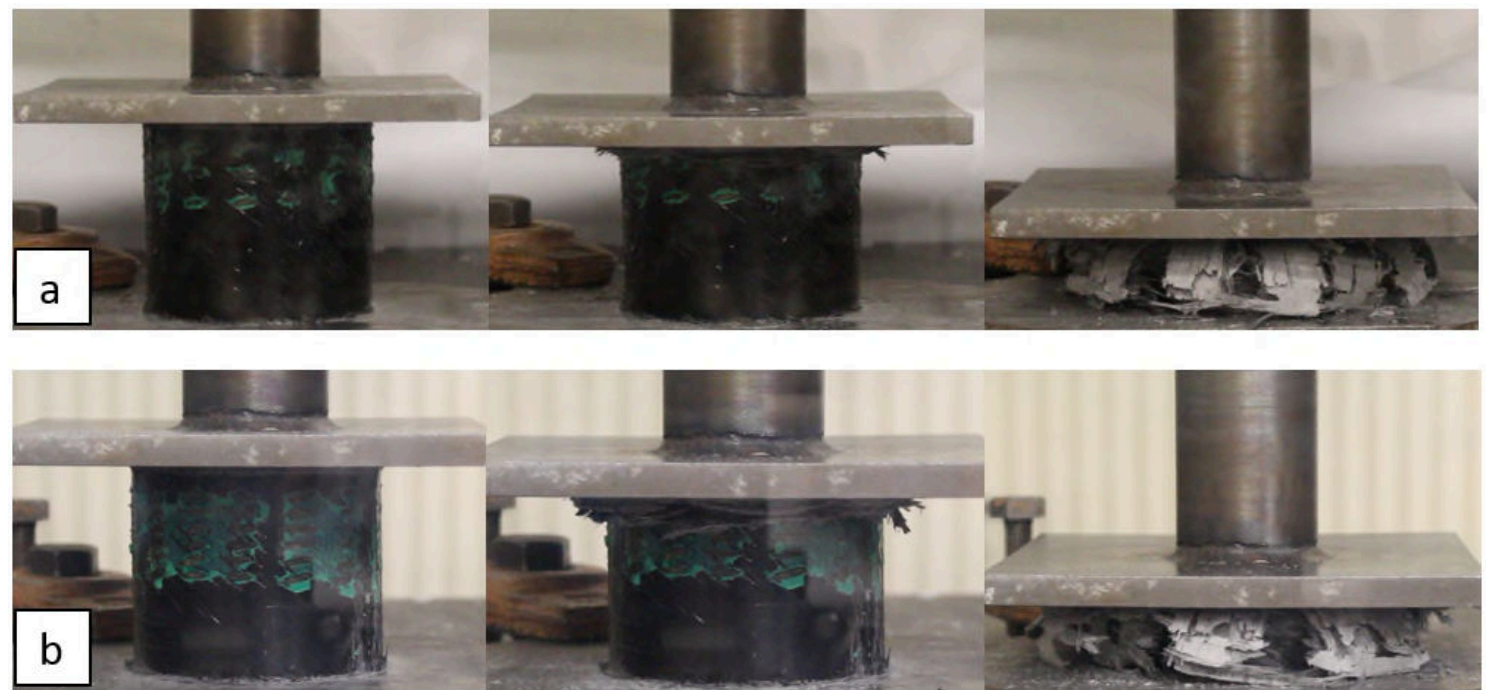

Figure 2. Various crushing stages of stitched composite sections, a) 10-20-30 mm, b) 10-15-20-25-30-35 mm.

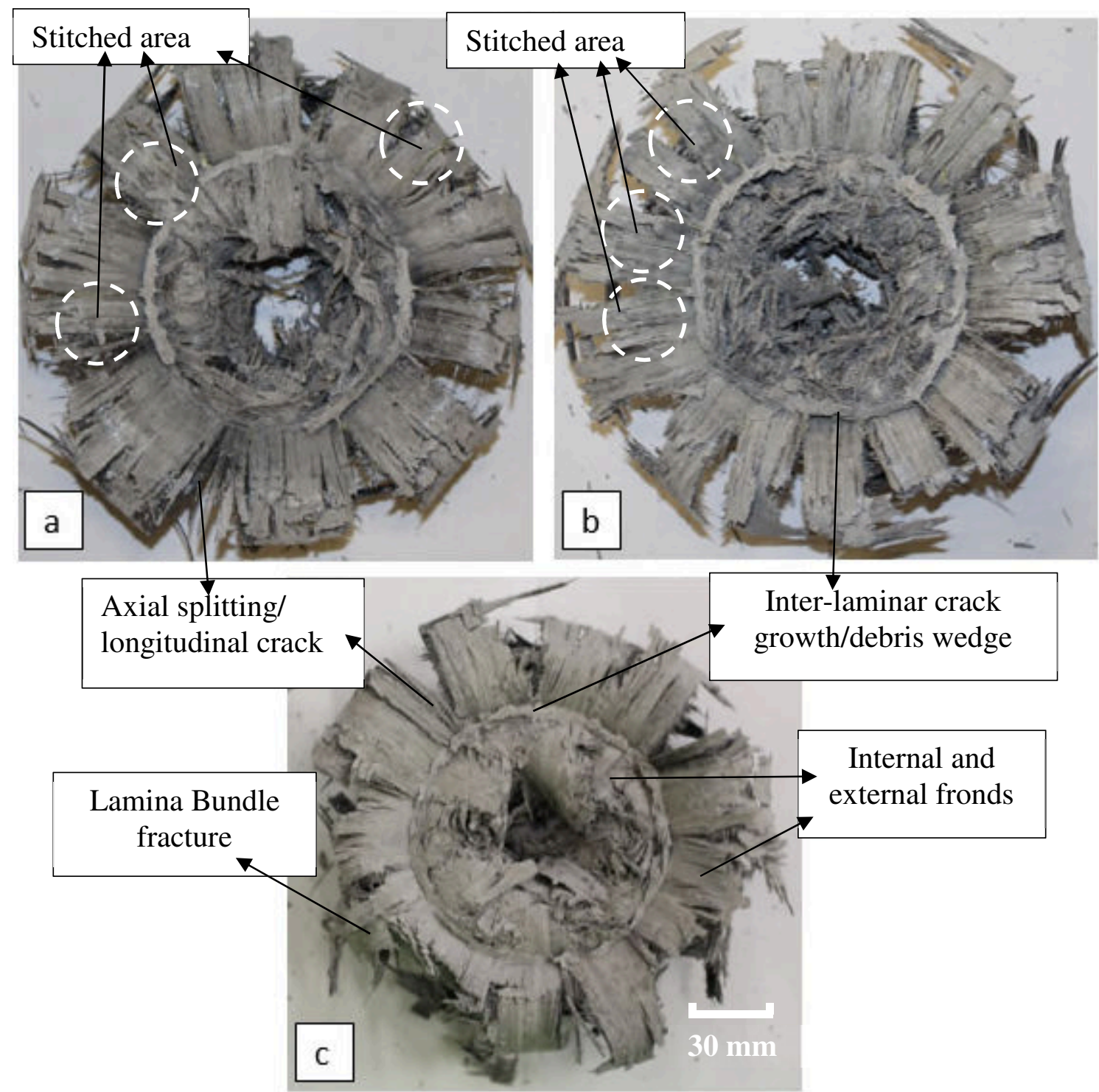

Figure 3. Plane view of crushed multi-stitched composite tubes. 
Introducing stitching to the very top of the composite section leads to catastrophic failure mechanism and buckling in the mid-section of the specimen. Therefore, in all of the designs, the through-thickness stitching is introduced $10 \mathrm{~mm}$ from the top of the specimen onwards, to allow delamination and petals formation which is followed by progressive crushing through the specimen.

\section{Advances in Finite Element Modelling}

\subsection{Method of Approach}

The explicit finite element (FE) tool, LS-Dyna was used to model the multi-layered stitched and non-stitched composite crash absorbers. The Belytschko-Tsay shell elements were used as double-shell layers to reduce computational costs. In the element plane, the reference point of the fibre direction is applied using an integration point to the shell. The fibre direction and the thickness of the ply are then depending on the number of plies which are embedded with each shell element using an in-plane integration point concerning the stacking sequence. Six integration points were assigned to each shell with an allocated thickness of $0.25 \mathrm{~mm}$ to each layer. All the elements have half thickness on either side of the defined thickness, referred to as mid-surface. Therefore, to account for this, two shells were modelled as inner and outer shells with radii of $37.75 \mathrm{~mm}$ and $39.25 \mathrm{~mm}$, lengths of $80 \mathrm{~mm}$ and $77.5 \mathrm{~mm}$ respectively. The reduction of outer shell length to $2.5 \mathrm{~mm}$ is considered as a trigger mechanism in the model.

\subsection{Finite Element Modelling Setup}

The element size of $2.5 \mathrm{~mm} \times 2.5 \mathrm{~mm}$ quadrilateral shell was used with Mat_054/055 which is an improved version of the Chang-Chang criterion, with added compressive fibre failure mode and it also includes compressive and tensile fibre and matrix failure mechanisms. The hourglass was set at 10\% [30] and material properties are presented in Table 1 (GFRP TenCate E722).

Table 1 Material properties of GFRP (TenCate E772).

\begin{tabular}{cccccccc}
\hline \multicolumn{10}{c}{ GFRP (TenCate E772) } \\
\hline $\boldsymbol{E}_{\mathbf{1}}$ & $E_{2}$ & $G_{12}$ & $v_{12}$ & $\sigma_{u} 0^{\circ}$ & $\sigma_{u} 90^{\circ}$ & $\tau_{s}$ & $V_{f}$ \\
$(\mathrm{GPa})$ & $(\mathrm{GPa})$ & $(\mathrm{GPa})$ & & $(\mathrm{MPa})$ & $(\mathrm{MPa})$ & $(\mathrm{MPa})$ & $(\%)$ \\
\hline $39 \pm 3$ & $11.8 \pm 1$ & $3.2 \pm 0.5$ & 0.29 & $836 \pm 20$ & $29 \pm 2$ & $97 \pm 4$ & 58 \\
\hline
\end{tabular}

Energy absorption is achieved through different failure mechanism including interlaminar fracture (delamination). By utilising a double shell configuration, this delamination between 
the layers can be modelled using an energy-based contact card. The contact card, One_Way_Surface_To_Surface_Tiebreak, enables the model to implement energy release rates of $\mathrm{G}_{\mathrm{IC}}$ and $\mathrm{G}_{\mathrm{IIC}}$ between the two shells.

Once the maximum shear strength (SFLS) or normal strength (NFLS) is reached, the detachment of the defined tiebreak between the two shells initiates. The PARAM parameter of the surface which is referred to critical normal separation is only enabled to complete the failure separation when the SFLS and NFLS are not met. The separation failure of the contact card is driven by the interlaminar fracture toughness that determines the interlaminar strength of the material, which is based on the mechanical properties of the matrix material and the detachment of the shells are completed once interlaminar stress exceeds the matrix properties. Hence, tiebreak parameters, SFLS and NFLS are dependent upon the epoxy resin mechanical properties and PARAM is calculated based on Eqs 1, 2 and 3. The PARAM is $0.32 \mathrm{~mm}$ for stitched and $0.15 \mathrm{~mm}$ for non-stitched GFRP specimen (see Table 2 and Table 3).

The tiebreak algorithm nodes are attached by a linear spring and the surfaces start to debond when maximum stress criterion is reached, which results in a linear stress damage curve. The spring is removed when the critical separation is reached.

$$
\left(\frac{\sigma_{n}^{2}}{N F L S}\right)^{2}+\left(\frac{\sigma_{s}^{2}}{S F L S}\right)^{2}=1
$$

where normal stress noted as $\sigma_{n}$, shear stresses noted as $\sigma_{s}$, normal strength noted as NFLS, shear strength noted as SFLS and critical distance is noted as PARAM. The two surfaces begin to separate once the damage has initiated and the interfacial stresses are scaled down based on the critical separation distance-[30].

With a parametric study of Mode-I and Mode-II fracture toughness, the effect of the energy release rate was determined on the tiebreak process. It can be concluded that, in crushing simulation of composite cylindrical shells, the dominant failure during tiebreak failure process is Mode-I fracture. Hence, to simplify the approach, pure Mode-I delamination is assumed.

$$
G_{I C}=\frac{1}{2} \sigma_{n} \text { PARAM }
$$

PARAM is obtained by critical normal stress and energy release rate in Mode-I $\left(G_{I C}\right)$. Since a double shell configuration was used to represent all layers, and delamination can occur at all or nearly all layers during crushing process, the tiebreak was adopted to represent all layers as opposed to only two layers in the model. This is important because delamination dissipates energy and delamination can occur between all plies, therefore delamination interface is adopted accordingly. Hence, PARAM' accounts for the ratio of the number of layers in the 
composite section, $n_{\text {layers }}$ and the number of shells in the model $n_{\text {shells }}$ multiplied by PARAM (Tables 2 and 3).

$$
P A R A M^{\prime}=P A R A M \times \frac{n_{\text {layers }}}{n_{\text {shell }}}
$$

In order to prevent the nodes penetrating into the tubes (self-penetration), caused by the crushing platen, Automatic_Single_Surface contact card was used. Automatic_Node_To_Surface contact card was also used between the inner shell and the crushing platen with slave and master enabled respectively. To calibrate the model, nonphysical parameters based on parametric studies are evaluated and corrected. The maximum shear failure strains, DFAILS, maximum strain for matrix straining in tension and compression, DFAILM and maximum strain for fibre tension, DFAILT, were defined as 0.03, 0.02 and 0.02, respectively.

Table 2 Tiebreak input parameters (non-stitched)

\begin{tabular}{lllllllc}
\hline $\begin{array}{l}\boldsymbol{E}_{\mathbf{1}} \\
(\mathrm{GPa})\end{array}$ & $\begin{array}{l}\boldsymbol{E}_{\mathbf{2}} \\
(\mathrm{GPa})\end{array}$ & $\begin{array}{l}\boldsymbol{G}_{\boldsymbol{I C}} \\
\left(\mathrm{kJ} / \mathrm{m}^{2}\right)\end{array}$ & $\begin{array}{l}\boldsymbol{G}_{\boldsymbol{I I C}} \\
\left(\mathrm{kJ} / \mathrm{m}^{2}\right)\end{array}$ & $\begin{array}{l}\text { NFLS } \\
(\mathrm{MPa})\end{array}$ & $\begin{array}{l}\text { SFLS } \\
(\mathrm{MPa})\end{array}$ & $\begin{array}{l}\text { PARAM } \\
(\mathrm{mm})\end{array}$ & $\begin{array}{l}\text { PARAM' } \\
(\mathrm{mm})(\text { double shell })\end{array}$ \\
\hline $39 \pm 3$ & $11.8 \pm 1$ & 0.33 & 1.2 & 26 & 57 & 0.025 & 0.15 \\
\hline
\end{tabular}

Table 3 Tiebreak input parameters (stitched)

\begin{tabular}{lllllllc}
\hline $\begin{array}{l}\boldsymbol{E}_{\mathbf{1}} \\
(\mathrm{GPa})\end{array}$ & $\begin{array}{l}\boldsymbol{E}_{\boldsymbol{2}} \\
(\mathrm{GPa})\end{array}$ & $\begin{array}{l}\boldsymbol{G}_{\boldsymbol{I C}} \\
\left(\mathrm{kJ} / \mathrm{m}^{2}\right)\end{array}$ & $\begin{array}{l}\boldsymbol{G}_{\boldsymbol{I I C}} \\
\left(\mathrm{kJ} / \mathrm{m}^{2}\right)\end{array}$ & $\begin{array}{l}\text { NFLS } \\
(\mathrm{MPa})\end{array}$ & $\begin{array}{l}\text { SFLS } \\
(\mathrm{MPa})\end{array}$ & $\begin{array}{l}\text { PARAM } \\
(\mathrm{mm})\end{array}$ & $\begin{array}{l}\text { PARAM' } \\
(\mathrm{mm})(\text { double shell })\end{array}$ \\
\hline $39 \pm 3$ & $11.8 \pm 1$ & 0.69 & 1.2 & 26 & 57 & 0.052 & 0.32 \\
\hline
\end{tabular}

Through-thickness stitching improves delamination resistance and using an idealised finite element model to capture this resistance accurately predicts the behaviour of stitched composite structures. On previous studies of the authors, a DCB test was performed for stitched and nonstitched specimens and these results were used in this paper using One_Way_Surface_To_Surface_Tiebreak contact card (option 8) to capture delamination resistance. This technique has led to capture both stitched and non-stitched crack growth behaviour through FEA [34].

\subsection{Stitching Techniques}

Three different components were defined in the non-stitched model, the crushing platen, the outer shell and the inner shell. The energy-based contact was defined between the two shells, One_Way_Surface_To_Surface_Tiebreak with a static and dynamic coefficient of frictions of 0.3 and 0.2 respectively [29]. However, modelling of stitched locations required additional 
contact definitions to account the $\mathrm{G}_{\mathrm{IC}}$ difference between stitched and non-stitched specimens. The interlaminar energy rate in the model was implemented using two energy-based contact card, one with PARAM set to $0.15 \mathrm{~mm}$ for the non-stitched area and $0.32 \mathrm{~mm}$ for the stitched locations. This means the interface separation between the two shells initiates when it reaches this critical distance, hence the energy absorption increases.

In this double shell configuration, each shell is constructed from two separate shells, one acting as the trigger (see Figure 4, a and d) and one as the main body (see Figure 4, b and e). A tied contact is used to create a perfect bonding between the two shells and avoid deboning during the crushing process. In stitched locations, through-the-thickness reinforcement is utilised in addition to the same technique used for non-stitched one. The holes are $1 \mathrm{~mm}$ in diameter, and the mesh size is $0.1 \mathrm{~mm}$. In the delamination modelling, energy-based contact is used for the entire structure according to Table 2 and stitched locations are reinforced using the data presented in Table 3. The PARAM is set to $0.32 \mathrm{~mm}$ for stitched and $0.15 \mathrm{~mm}$ for non-stitched, when the crushing process reaches the stitching points, the Mode-I delamination resistance increases, and results into higher energy absorption. In experimental studies, Mode-I crack propagation resistance increases when it reaches the stitched regions, hence in the stitching locations, this has been implemented to capture the true likeliness of this increase of $G_{I C}$ in the stitched regions. Therefore, at the non-stitched regions, the contact has the parameters shown in Table 2, and at the stitched regions the related contact parameters are presented in Table 3. The data in Table 2 and 3 are based on DCB and 3ENF testing specimens to determine the energy release rate of Mode-I and Mode-II. The main parameter to implement in the contact card lays within the PARAM to define the critical separation of the surface and this parameter delays the shell separation based on critical crushing distance and hence improves energy absorption capability which is similar behaviour of stitched regions in composite tubes. In Figure 4, $\mathrm{g}$ and $\mathrm{h}$, the assembly of inner and outer shells are shown and the full assembly is shown in Figure 4, i. 

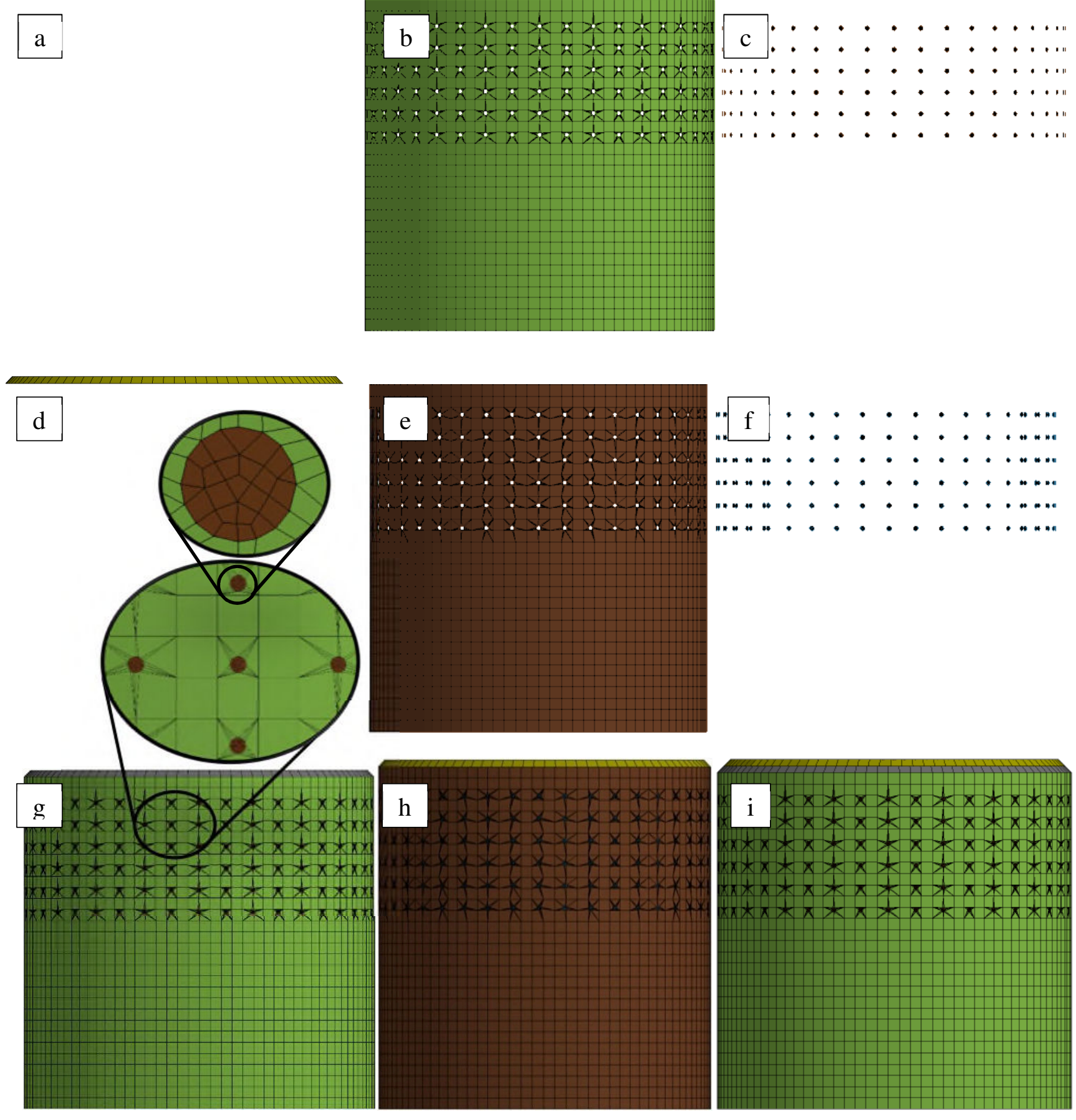

Figure 4. a) trigger mechanism of the outer shell, b) main body structure of the outer shell, c) stitching of outer shell, d) trigger mechanism of the inner shell, e) main body structure of the inner shell, f) stitching of inner shell, g) the outer shell assembly, h) the inner shell assembly, i) stitched double-shell assembly.

The value of PARAM represents potential delamination within all layers. In the stitched area, PARAM value represents the through-thickness stitching reinforcement. However, this value depends on the number of stitches in the circumference of the specimen, in all specimens, 25 stitches were used in each row. Using a DCB test which was carried out in previous study of the authors [34] the modelling technique of this method was validated. Therefore, in this study a coherent elaboration is carried out to study the density of stitching on composite tubular 
structures comprehensively. The value of PARAM is constant which allocates each stitching point a value of $0.0128 \mathrm{~mm}$. The main structure of the tube was modelled as internal and external shell in double configuration. The Element_generation and Fill_Holes features were used to model the holes based on the satisfactory generated mesh in shells. The Part ID number is changed to match the main structure either inner or outer shell.

\subsection{Pattern Design}

The numerical investigations have been carried out to improve the energy absorption capability of composite absorbers. The multi-stitching of 10-15-20-25-30-35 mm with $6 \mathrm{~mm}$ distance between each stitched point has shown a 15\% improvement in energy absorption. Since the 6 $\mathrm{mm}$ horizontal gap was used in section 2 (experiment), in this section, $3 \mathrm{~mm}, 9 \mathrm{~mm}$ and $18 \mathrm{~mm}$ are chosen to implement the effect of a zig-zag pattern in this study. The proposed study is shown in Figure 5 as the alignment of stitching patterns: a- $3 \mathrm{~mm}, \mathrm{~b}-6 \mathrm{~mm}$, c- $9 \mathrm{~mm}$ and d$18 \mathrm{~mm}$, and zig-zag stitching: e- $3 \mathrm{~mm}$, f- $6 \mathrm{~mm}$, g- $9 \mathrm{~mm}$ and h- $18 \mathrm{~mm}$. This enables us to study the effect of stitching patterns on the energy absorption capability of composite absorbers. 


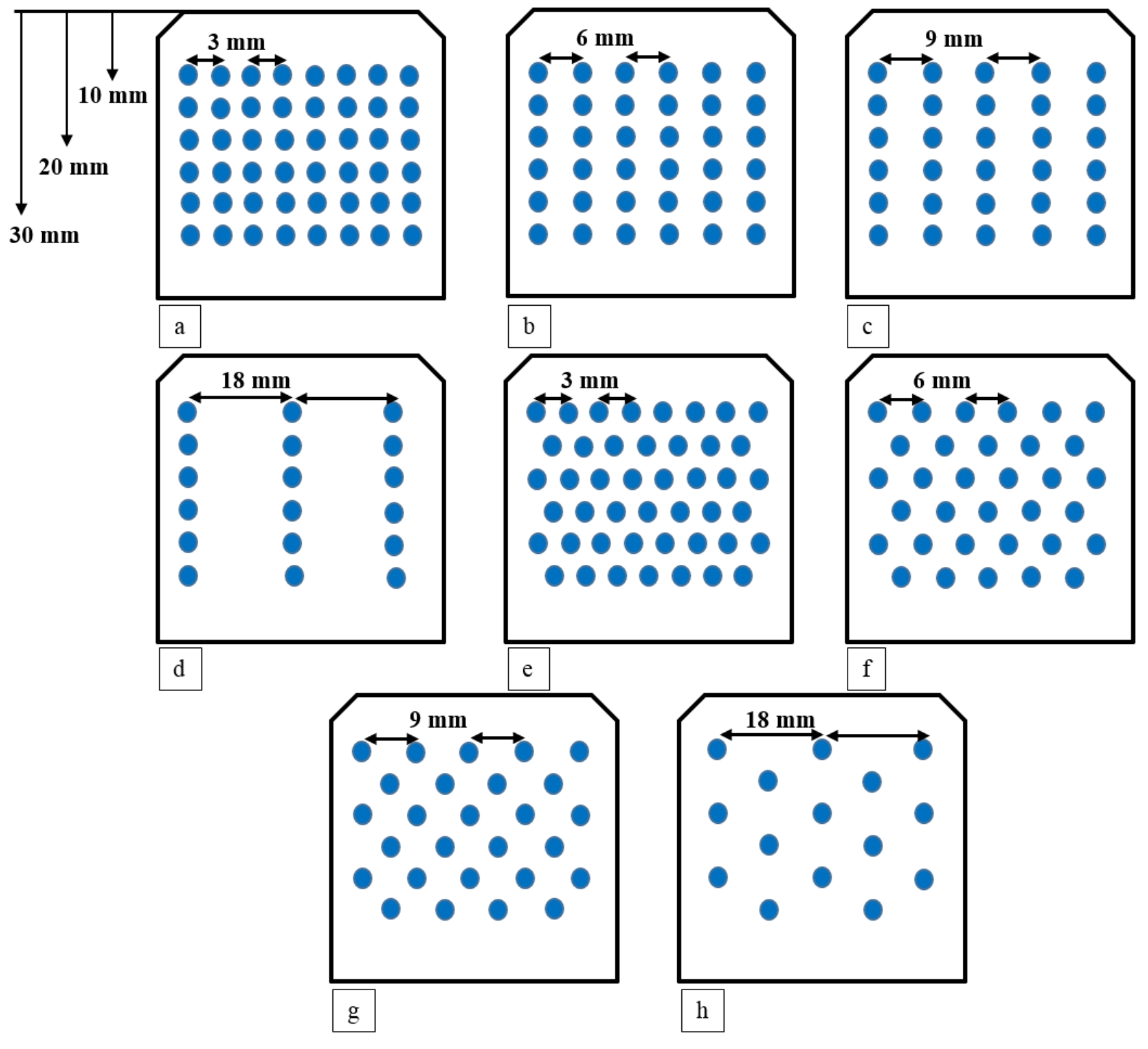

Figure 5. Various design of stitched composite tube; stitching density vs pattern.

\subsection{Results and Discussion}

Five specimens were tested in each case of study, five cases were axially tested under quasistatic loading and the mean deviation of the result is plotted in Figure 6 a, and similarly five specimens were tested for stitched specimen with pattern of 10-15-20-25-30-35 mm (see Figure 6 b). All simulation results are smoothed using SAE $300 \mathrm{~Hz}$ filter in post-processing [33]. Figure 7 illustrates the obtained data, which are filtered and unfiltered. 

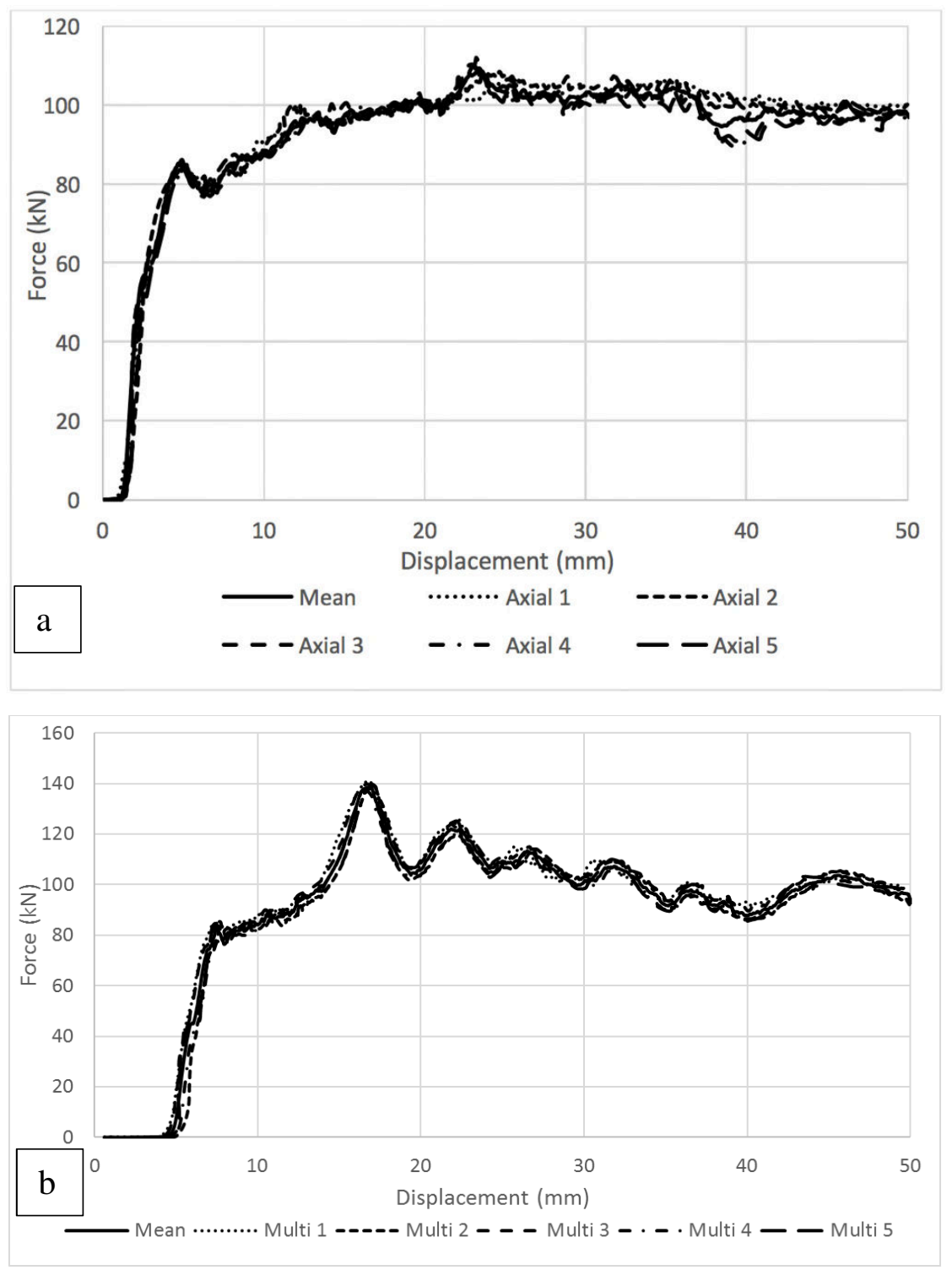

Figure 6. Five tests with mean deviation, a) non-stitched, b) stitched (10-15-20-25-30-35 mm)

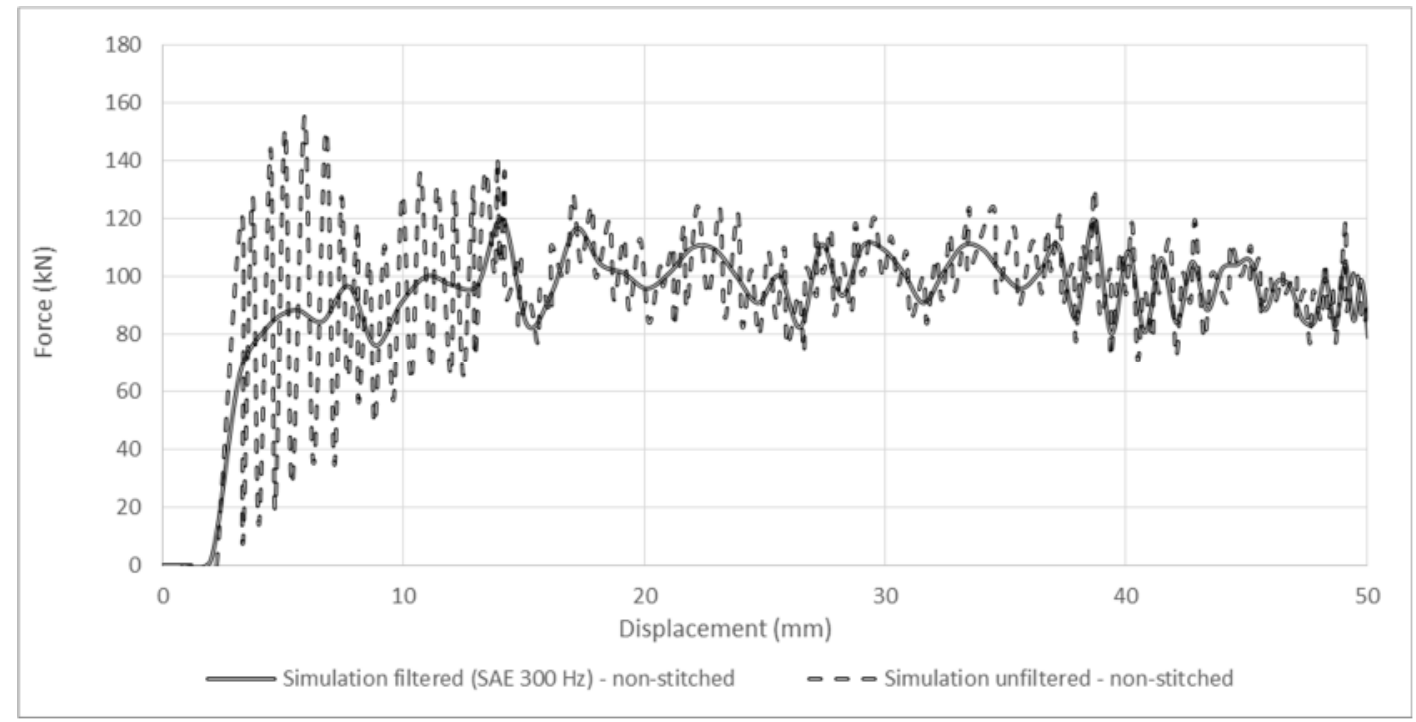

Figure 7. Filtered (SAE $300 \mathrm{~Hz})$ and unfiltered data from non-stitched. 
To satisfy quasi-static conditions, it is important that the load is applied in a manner that would yield a minimal inertial effect on the results and the ratio of the kinetic energy to the internal energy must be reasonably small.

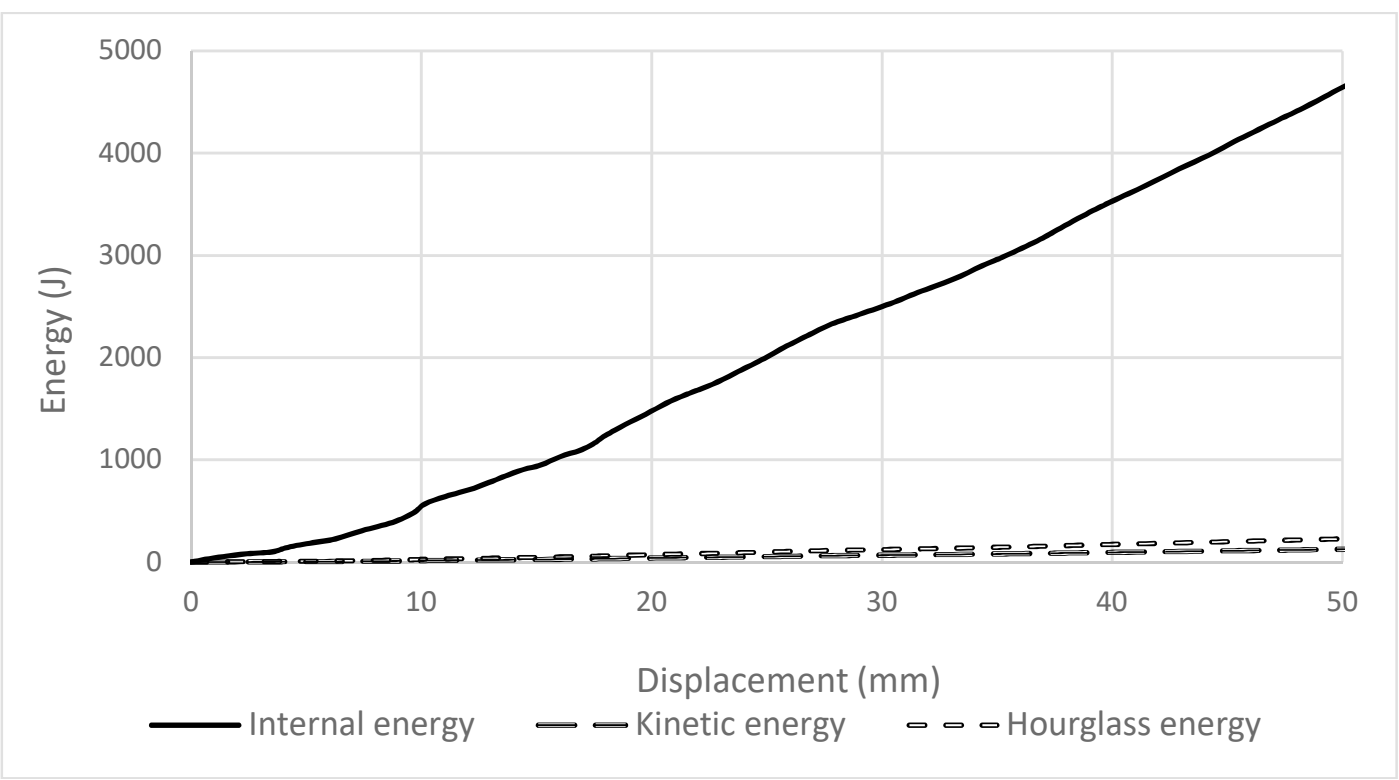

Figure 8. Numerical simulation, Internal, external and Hourglass energy comparison.

The results indicate that the density of stitched zones increases the energy absorption capability of composite absorbers. Figure 9 illustrates the numerical results of 10-20-30 mm stitched specimen against experimental study. The initial peak of $80 \mathrm{kN}$ followed by three sudden increase in energy absorption capability is clearly observed due to through-thickness reinforcement. This sudden increase in energy absorption does precisely coincide with the stitching locations. The sudden increase is observed after the initiation of the crushing due to higher friction between the plies and the petals to the crushing platen. This behaviour leads to higher bending moment of the petals and brittle failure mechanism which is a combination of lamina bending and transverse shearing modes. 


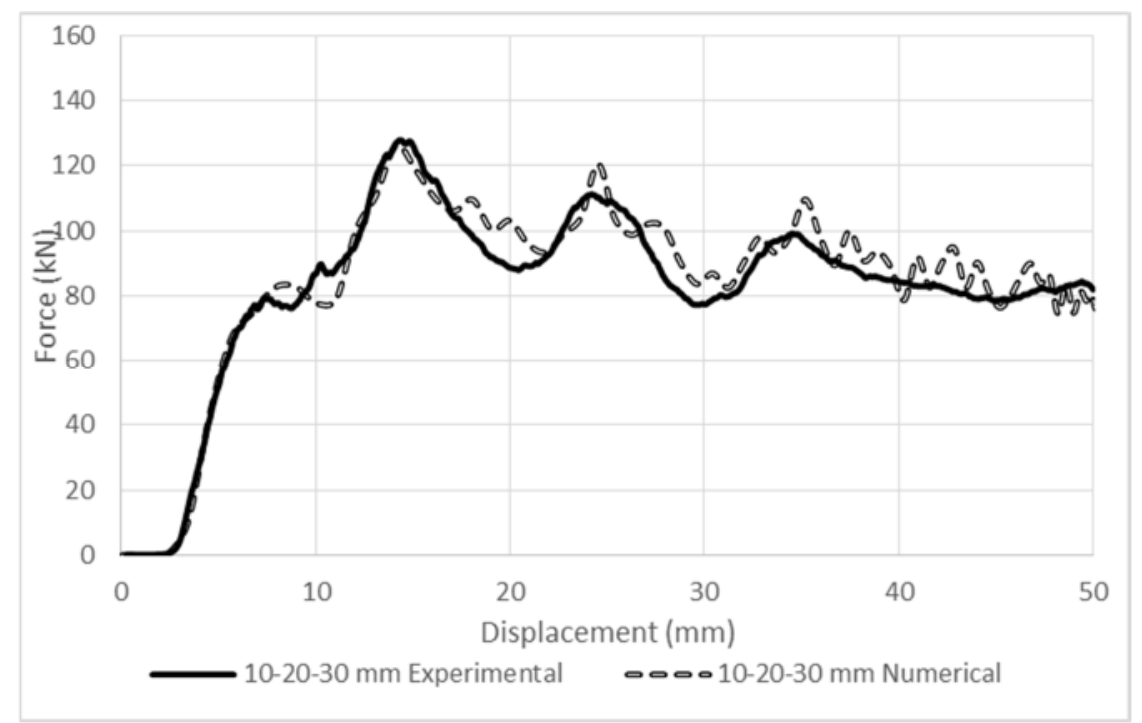

Figure 9. Experimental testing of 10-20-30 mm against relative numerical simulation

Figure 10 illustrates the numerical results of various density and pattern studies. Aligned and zig-zag stitching has a marginal effect on the overall performance of the composite tube concerning energy absorption capability, however, stitching density greatly influences the progressive crushing of multi-stitched composite sections. Low stitching density results into lower crack growth resistance, which degrades the structural integrity of multi-stitched composite absorbers compared with non-stitched specimens. Through-thickness stitching causes a localised increase of load, which is followed by decrease of load as a result of additional damages to the structure. This phenomenon leads to fibre breakage, fibre and matrix separation, resin pocket formation around the stitched area (Figure 10i). The results illustrate that higher stitching density significantly improves both local and global energy absorption capability of composite structures.

The difference in the slope of the curves in Figure $10 \mathrm{a}$, is related to the experimental test adjustment. High stitching density improves energy absorption capability as shown in Figure 10, part $\mathrm{b}$ and $\mathrm{c}$. The $3 \mathrm{~mm}$ apart stitching, shows significant improvement in energy absorption capability and improvement of crushing mean force by $120 \mathrm{kN}$ (see Figure $10 \mathrm{~b}$ ). 

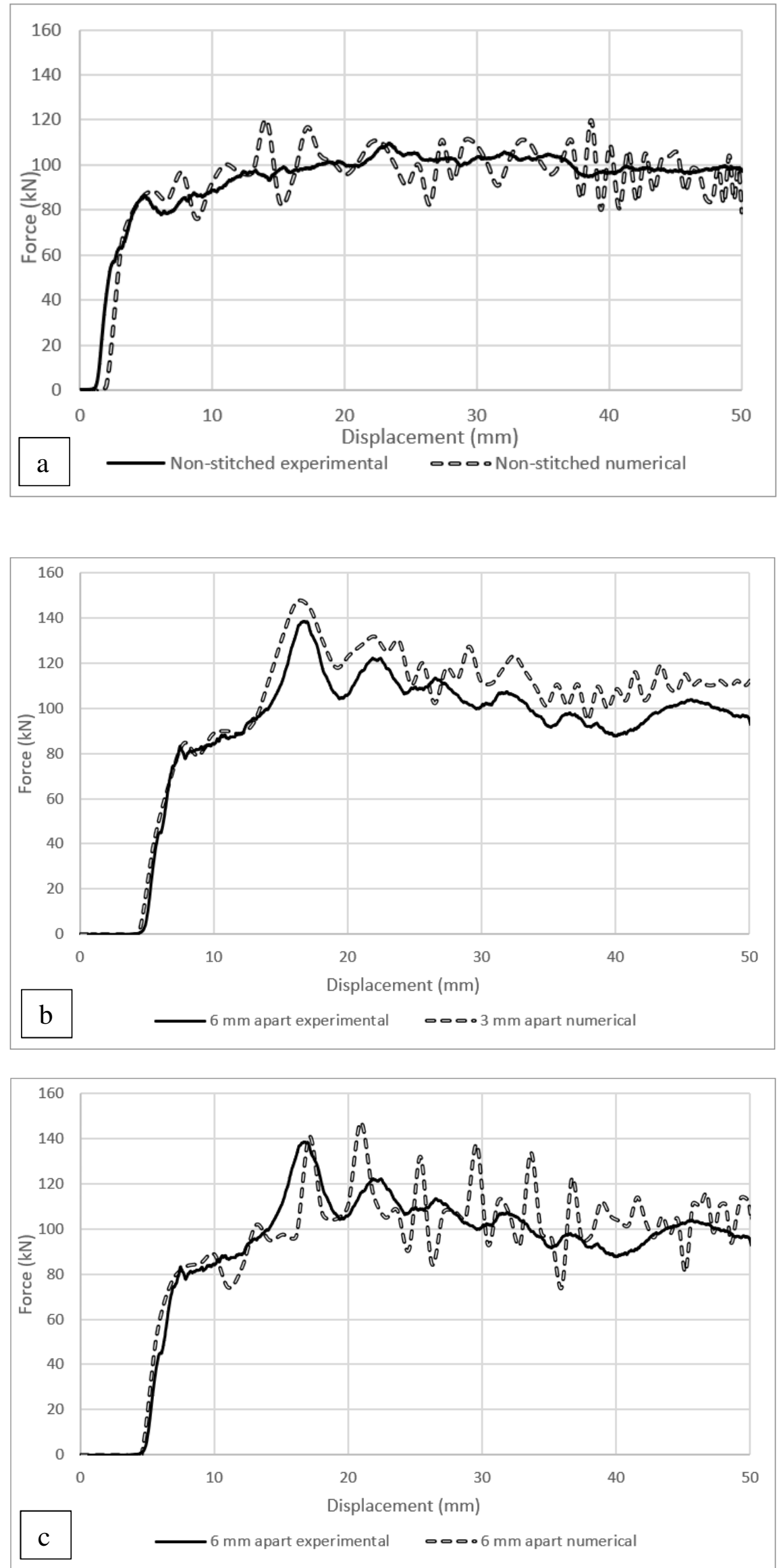

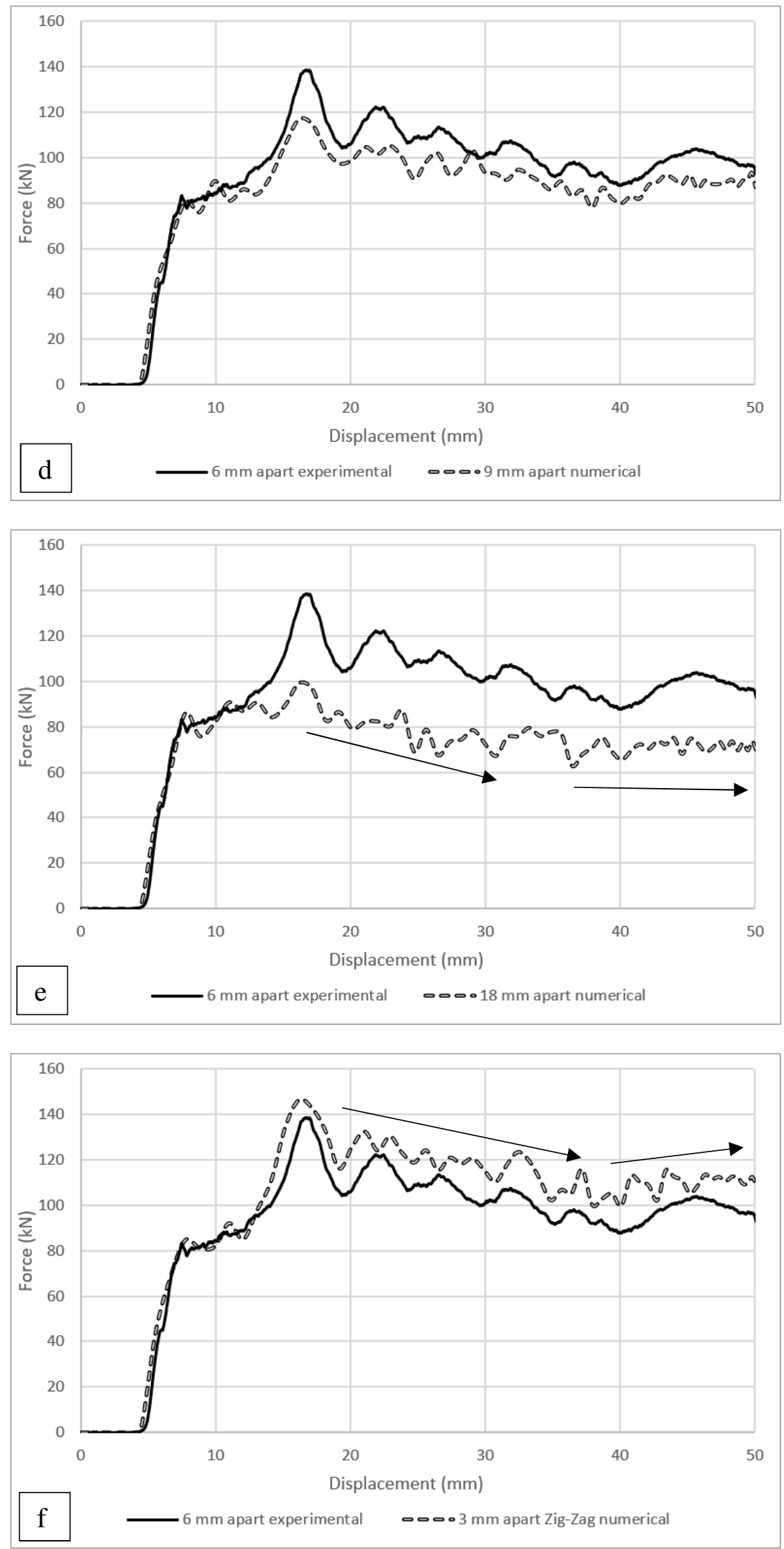

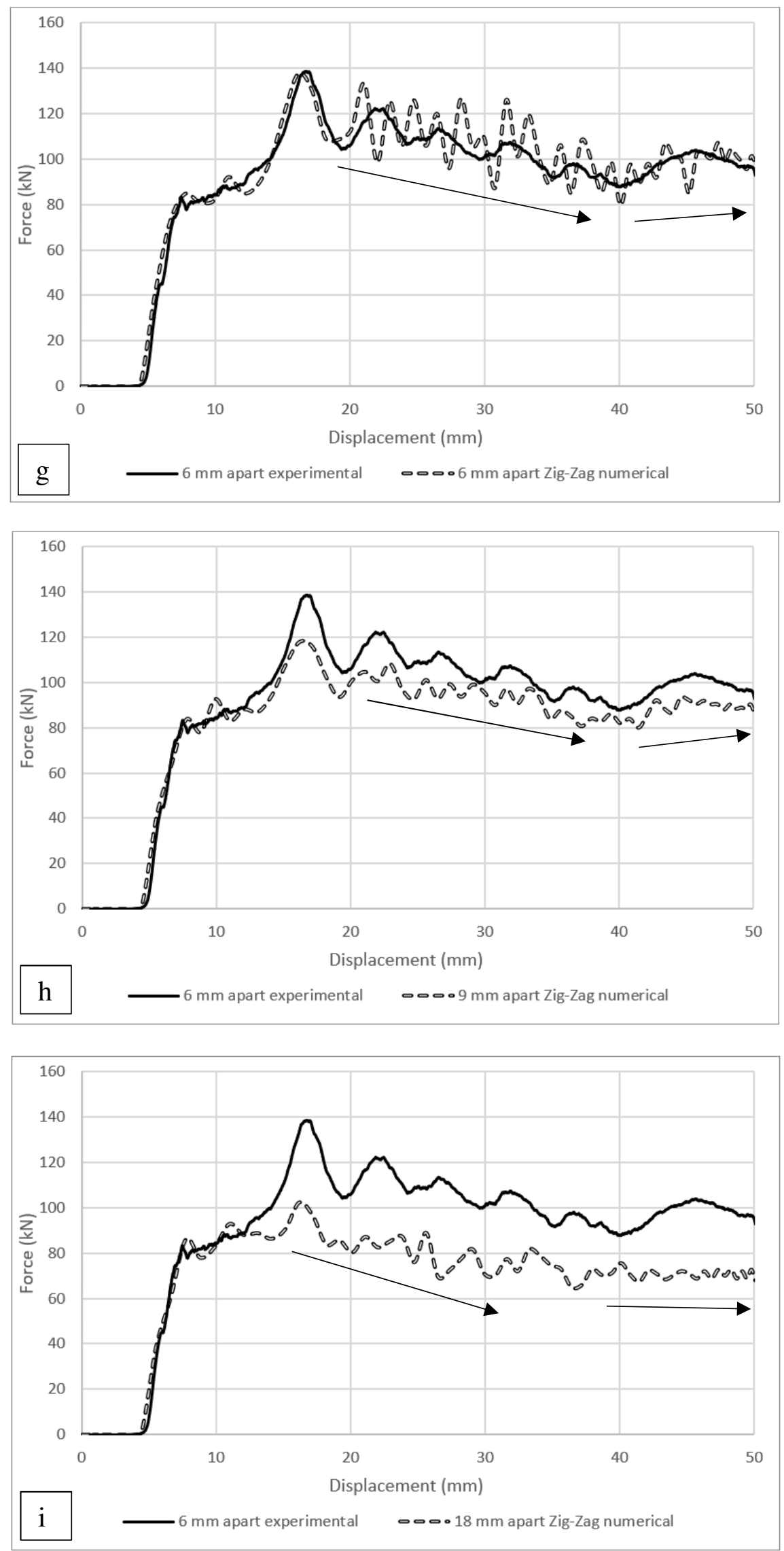

Figure 10. Numerical results of stitching density and zig-zag study, a) non-stitched experimental and numerical results, b) $3 \mathrm{~mm}$ apart numerical compared with $6 \mathrm{~mm}$ apart experimental results, c) $6 \mathrm{~mm}$ apart numerical compared with $6 \mathrm{~mm}$ apart experimental results, d) $9 \mathrm{~mm}$ apart numerical compared with $6 \mathrm{~mm}$ apart experimental 
results, e) $18 \mathrm{~mm}$ apart numerical compared with $6 \mathrm{~mm}$ apart experimental results, f) $3 \mathrm{~mm}$ apart zig-zag numerical compared with $6 \mathrm{~mm}$ apart experimental results, g) $6 \mathrm{~mm}$ apart zig-zag numerical compared with $6 \mathrm{~mm}$ apart experimental results, h) $9 \mathrm{~mm}$ apart zig-zag numerical compared with $6 \mathrm{~mm}$ apart experimental results, i) $18 \mathrm{~mm}$ apart zig-zag numerical compared with $6 \mathrm{~mm}$ apart experimental results

The total displacement of the crushing platen was fixed to $50 \mathrm{~mm}$ in the $\mathrm{z}$-direction. In the experiment, the space between the specimen and crushing platen varied causing legend to shift slightly. To have all the curves finish at $50 \mathrm{~mm}$, no shifting of the $\mathrm{x}$-axis of the graph was considered for the experimental results and only the FEA results were shifted in the $\mathrm{x}$-axis to match the experiment. In Table 4, the experimental results are compared with FEA results. The initial peak $\left(\mathrm{F}_{\mathrm{max}}\right)$, mean force $\left(\mathrm{F}_{\mathrm{m}}\right)$ and specific energy absorption (SEA) are compared. The disagreement between experimental data and numerical results is less than $3 \%$. The percentage error is calculated based on SAE value.

Table 4 Experimental and numerical results comparison

\begin{tabular}{ccccc}
\hline Specimens & $\mathbf{F}_{\max }(\mathbf{k N})$ & $\mathbf{F}_{\mathrm{m}}(\mathbf{k N})$ & SEA $(\mathbf{k J} / \mathbf{k g})$ & $\begin{array}{c}\text { Error } \\
(\%)\end{array}$ \\
\hline Non-stitched experimental & $84 \pm 2$ & $100 \pm 2$ & $64 \pm 2$ & \\
\hline Non-stitched numerical & 86 & 99 & 66 & 3 \\
\hline $10-20-30$ mm experimental & $77 \pm 2$ & $95 \pm 2$ & $61 \pm 2$ & 62 \\
\hline $10-20-30$ mm numerical & 78 & 96 & $74 \pm 2$ & 3 \\
\hline $10-15-20-25-30-35$ mm experimental & $83 \pm 2$ & $116 \pm 2$ & 117 & 76 \\
\hline $10-15-20-25-30-35$ mm numerical & 84 & & 3 \\
\hline
\end{tabular}

The effect of stitching pattern on the energy absorption capability of composite sections is further studied based on a new design with the highest densification in comparison with previous cases in section 3.5. In the previous study of authors [29], the vertical distance of the stitching and number of stitching rows were experimentally studied, and it was concluded that as the stitching rows become closer to each other the energy absorption significantly improves. In the current study, it was established that as the horizontal stitching points are closer, the energy absorption significantly improves. Hence, another design is proposed, which is constructed from both studies. The horizontal distance is set to $3 \mathrm{~mm}$, and a vertical distance is $2.5 \mathrm{~mm}$ which is reduced from $5 \mathrm{~mm}$ in experimental studies. The stitching locations are, 10 , $12.5,15,17.5,20,22.5,25,27.5,30,32.5,35 \mathrm{~mm}$ from the top of the specimen, which has 11 rows of stitching locations (see Figures 11 and 12). 

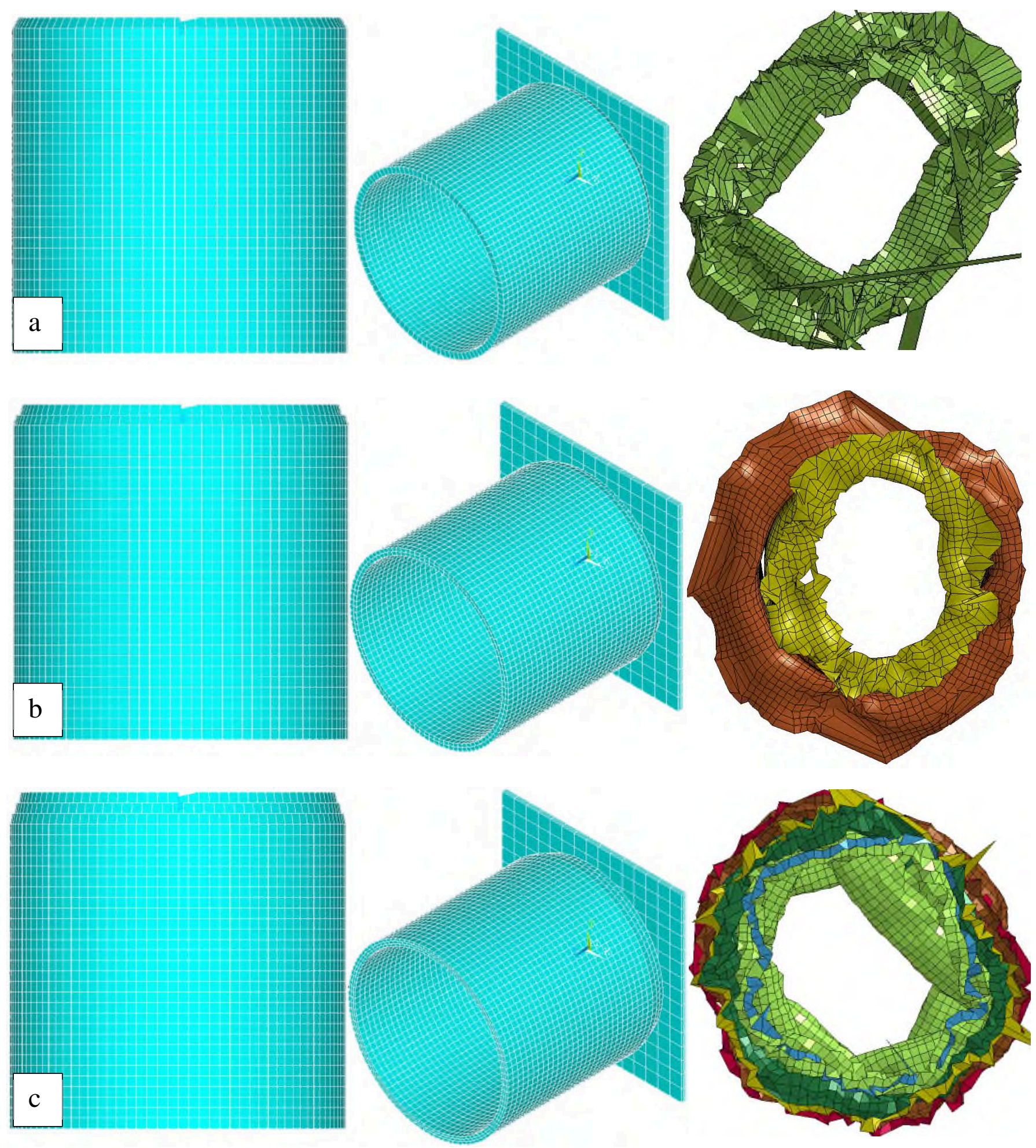

Figure 11. The number of shell configuration, a) 1 shell, b) 2 shells and c) multi-stitched using PARAM technique. 


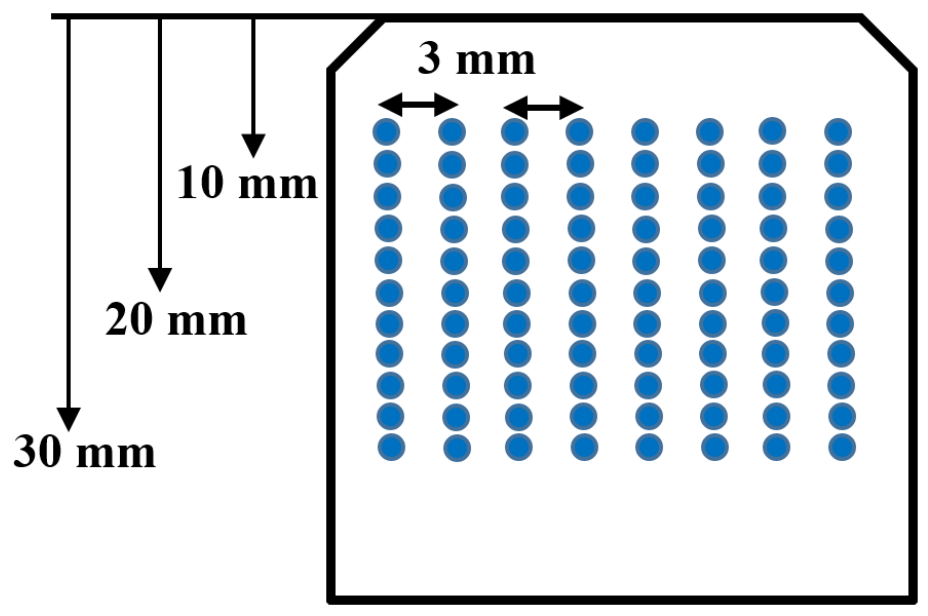

Figure 12. Final design of stitched composite tubes $-3 \mathrm{~mm}$ (horizontal) and $2.5 \mathrm{~mm}$ (vertical) distance.

In the final design, the mean crushing force increased to $150 \mathrm{kN}$ which leads to $91 \mathrm{~kJ} / \mathrm{kg}$. It can be concluded that the density of stitches significantly influences the progressive crushing behaviour of composite tubes. In real manufacturing, this high density might not be achievable with hand techniques and additional insertion of resin will be required to obtain a fully bonded fibre and matrix phases (see Figure 13).

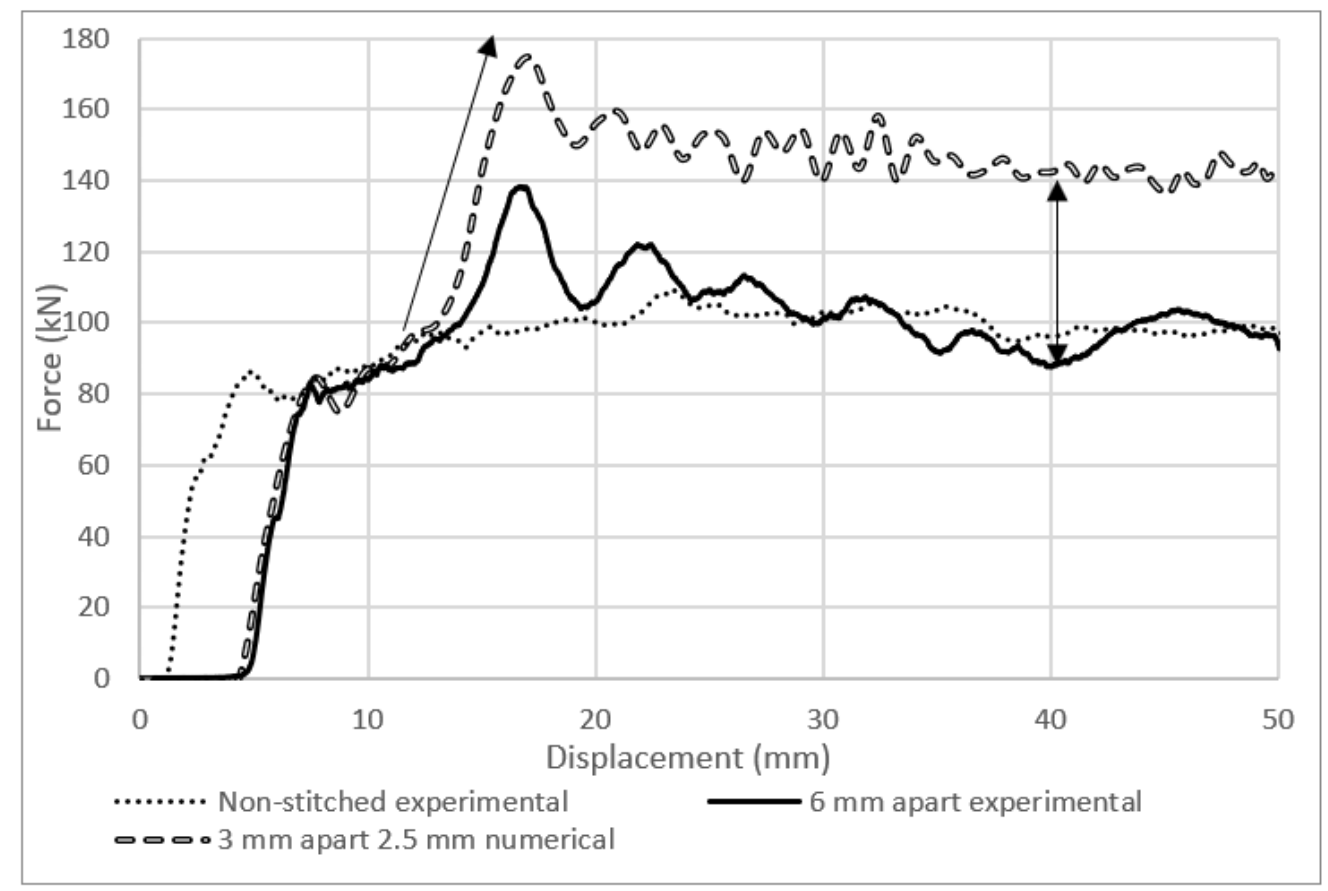

Figure 13. Comparison of force-displacement of numerical and experimental studies.

Figure 14 illustrates the specific energy absorption values of different pattern designs. The highest value was obtained from the results of $3 \mathrm{~mm}$ and $2.5 \mathrm{~mm}$ gaps in vertical and horizontal directions respectively, with the total value of $91 \mathrm{~kJ} / \mathrm{kg}$, which showed $17 \%$ increase from 
multi-stitched design of $10,15,20,25,30,35 \mathrm{~mm}$, and $32 \%$ increase from the non-stitched specimen. This is followed by $3 \mathrm{~mm}$ apart aligned and zig-zag combination, with values of 80 $\mathrm{kJ} / \mathrm{kg}$, which indicates a $6 \%$ increase from stitched specimen and a $21 \%$ increase from the nonstitched specimen.

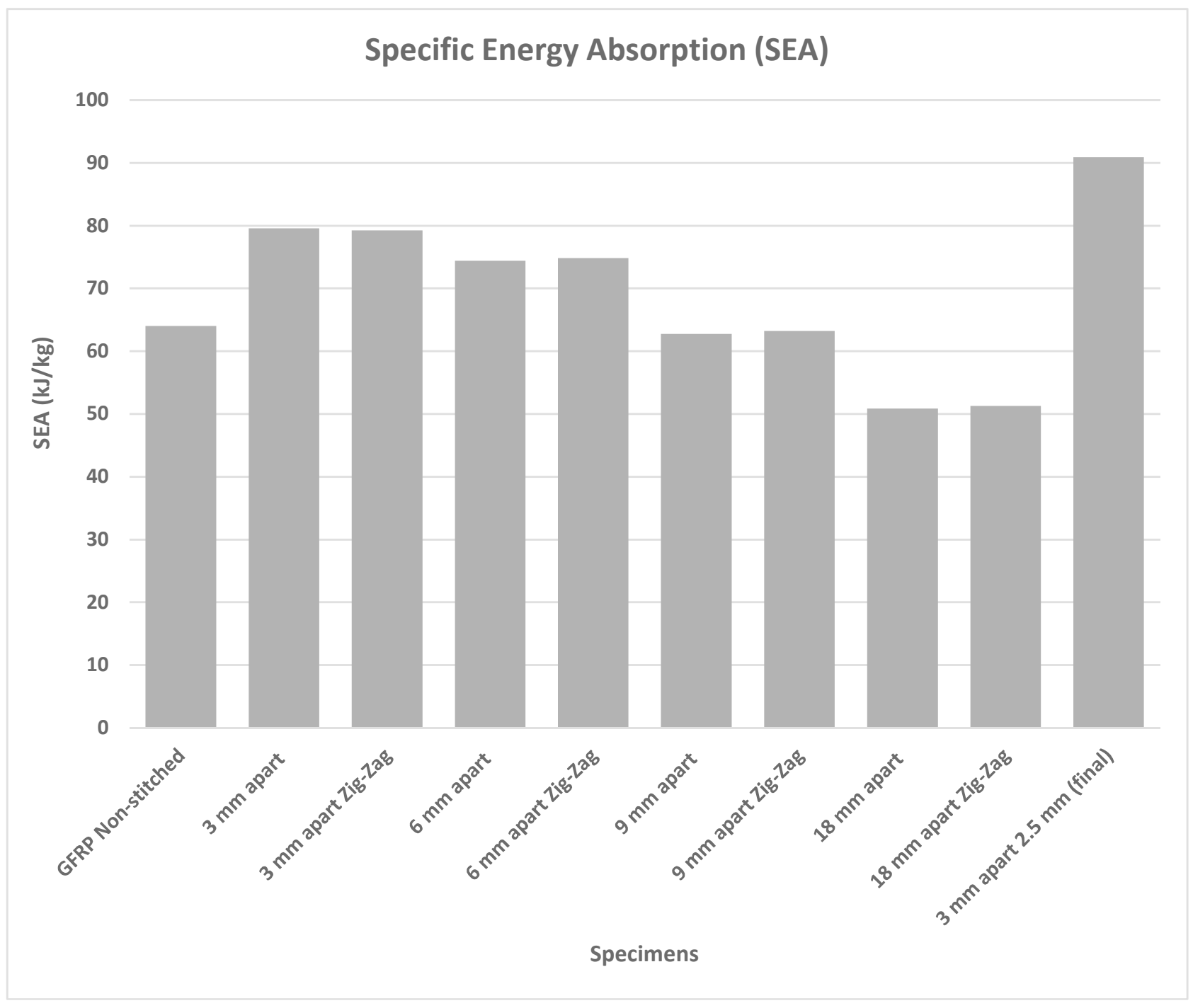

Figure 14. Comparison of SEA of various design of stitching pattern (numerical results).

\section{Conclusions}

In this study, the effect of stitching pattern/density on energy absorption capability of composite tubular structures was studied. The proposed patterns were studied using the calibrated FEM, and a correlation between the density of stitched locations and specific energy absorption was established. All dense stitched specimens, showed higher energy absorption capabilities compared with non-stitched specimens. 
Modelling of stitched locations was established using an energy-based contact technique. This approach was efficient and showed the accurate prediction of energy absorption capability and relative collapse modes in GFRP stitched and non-stitched specimens. Various pattern designs were proposed to investigate the effect of stitching pattern design in the straight and zig-zag combination. The effect of the zig-zag combination was minimal and no significant result was obtained. The horizontal and vertical distance between the stitched locations affected the energy absorption capability of composite sections. The $3 \mathrm{~mm}$ apart model showed a $21 \%$ increase and reducing the vertical distance of the stitches by half showed a $32 \%$ increase in energy absorption capability in comparison with non-stitched specimens.

\section{References}

[1] Liu, Q. Xing, H. Ju, Y. Ou, Z. Li, Q. Quasi-static axial crushing and transverse bending of double hat shaped CFRP tubes, Compos Struct 2014;117:1-11.

[2] Meidell, A. Computer-aided material selection for circular tubes designed to resist axial crushing, Thin-Walled Structures 2009;47:962-9.

[3] Rabiee, A. and Ghasemnejad, H. Progressive Crushing of Polymer Matrix Composite Tubular Structures: Review, Open Journal of Composite Materials, 2017;7:14-48.

[4] Saijod, T.W.L. Said, M.R. Yaakob, M.Y. On the effect of geometrical designs and failure modes in composite axial crushing: A literature review, Composite Structures, 2012; 94:803-812.

[5] Tong, L. Mouritz, A.P. Bannister, M. 3D fibre reinforced polymer composites. ELSEVIER, ISBN-13 (2002).

[6] Pan, T.S. Herrington, P.D. Local buckling of stitched composite laminate, Compos Part B: Eng, 1999;30(8):833-840.

[7] Jain, L.K. Mai, Y-W. On the effect of stitching on Mode I delamination toughness of laminated composites, Compos Sci Technol, 1994;51(3):331-345. 
[8] Dransfield, K.A. Jain, L.K. Mai, Y.-W. On the effects of stitching in CFRPs-I. Mode I delamination toughness, Compos Sci Technol, 1998;58(6):815-827.

[9] Shu, D. Mai, Y.W. Effect of stitching on interlaminar delamination extension in composite laminates, Compos Sci Technol, 1993;49(2):165-171.

[10] Aymerich, F. Onnis, R. Priolo, P. Analysis of the fracture behaviour of a stitched single-lap joint, Compos Part A: Appl Sci Manuf, 2005;36(5):603-614.

[11] Liu, Q. Fu, J. Ma, Yotao. Zhang, Y. Li, Q. Crushing responses of energy absorption behaviors of multi-cell CFRP tubes, Thin-walled Structures, 2020;155:106930.

[12] Liu, Q. Liufu, K. Cui, Z. Li, J. Fang, J. Li, Q. Multiobjective optimization of perforated square CFRP tubes for crashworthiness, Thin-walled Structures, 2020;149:106628.

[13] Fu, J. Lie, Q. Linufu, K. Deng, Y. Fang, J. Li, Q. Design of bionic-bamboo thin-walled structures for energy absorption, Thin-walled Structures, 2019;135:400-413.

[14] Saito H, Inai R, Yokoyama A, Hamada H. Basic study of progressive crushing mechanism. Key Eng Mater 2000;177-180:321-326.

[15] Warrior NA, Turner TA, Robitaille F, Rudd CD. The effect of interlaminar toughening strategies on the energy absorption of composite tubes. Composites: Part A 2004;35:431-437.

[16] Jacob GC, Fellers JF, Simunovic S. and Starbuck M. Energy absorption in polymer composites for automotive crashworthiness. Journal of Composite Materials 2002;36:813-50.

[17] Cauchi-Savona S. Zhang C. Hogg P. Optimisation of crush energy absorption of noncrimp fabric laminates by through-thickness stitching. Compos A: Appl Sci Manuf, 2011;42(7):712-722.

[18] Cauchi Savona S, Hogg PJ. Effect of fracture toughness properties on the crushing of flat composite plates. Compos Sci Technol 2006;66:2317-2328. 
[19] Solaimurugan S and Velmurugan R. Influence of fibre orientation and stacking sequence on petalling of glass/polyester composite cylindrical shell under axial compression. Int Jnl of Sol and Struc 2007;44:6999-7020.

[20] Solaimurugan S and Velmurugan R. Progressive crushing of stitched glass/polyester composite cylindrical shells. Compos Sci Technol 2007;67:422-437.

[21] Ghasemnejad H and Hadavinia H. Off-axis crashworthiness characteristic of woven glass/epoxy composite box structures. J. Reinf Plast Comp. 2010;29(15):2306-2330.

[22] Zhao, N. Rödel, H. Herzberg, C. Gao, S.L. Krzywinski, S. Stitched glass/PP composite. Part I: tensile and impact properties, Composites Part A, 2009;40:635-643.

[23] Solaimurugan, S. and Velmurugan, R. Progressive crushing of stitched glass/polyester composite cylindrical shells. Compos Sci Technol, 2007;67:422-437.

[24] Huang, J. Wang, X. Numerical and experimental investigations on the axial crushing response of composite tubes, Compos Struct, 2009;91(2):222-228.

[25] Mamalis, A.G. Manolakos, D.E. Loannidis, M.B. Papapostolou, D.P. The static and dynamic axial collapse of CFRP square composite tubes: finite element modelling, Compos Struct, 2006;74(2):213-225.

[26] Palanivelu, S. Paepegem, W. Degrieck, J. Kakogiannis, D. Ackeren, J. Hemelrijck, D. Parametric study of crushing parameters and failure patterns of pultruded composite tubes using cohesive elements and seam, Part I: central delamination and triggering modelling, Polym Test, 2010;29(6):729-741.

[27] Palanivelu, S. Paepegem, W. Degrieck, J. Kakogiannis, D. Ackeren, J. Hemelrijck, D. Parametric study of crushing parameters and failure patterns of pultruded composite tubes using cohesive elements and seam, Part II: multiple delaminations and initial geometric imperfections, Polym Test, 2010;29(7):803-814. 
[28] Bussadori, B.P. Schuffenhauer, K. Scattina, A. Modelling of CFRP crushing structures in the explicit crash analysis, Compos Part B-Eng, 2014;60:725-735.

[29] Rabiee, A. Ghasemnejad, H. Effect of multi stitched locations on high-speed crushing of composite tubular structures, Composites Part B: Engineering, 2016;100:164-175.

[30] Siromani, D. Awerbuch, J. Tan,T.-M. Finite element modeling of the crushing behavior of thin-walled CFRP tubes under axial compression, Compos B Eng, 2014;64:50-58.

[31] Mamalis, A.G. Manolakos, D.E. Demosthenous, G.A. Ioannidis, M.B. Crashworthiness of Composite Thin-walled Structural Composites, Technomic Pub, Lancaster (1998).

[32] Ghasemnejad H, Blackman BRK, Hadavinia H and Sudall B. Experimental studies on fracture characterisation and energy absorption of GFRP composite box structure. Composite Structures 2008;88(2):253-261.

[33] Rabiee, A. and Ghasemnejad, H. Laminate Tailoring of Composite Tubular Structures to Improve Crashworthiness Design at Off-Axis Loading, Open Journal of Composite Materials, 2018;8:84-109.

[34] Rabiee, A. and Ghasemnejad, H. Lightweight design to improve crushing behaviour of multi-stitched composite tubular structures under impact loading, Thin-Walled Structures, 2019;135:109-122. 
$2020-11-26$

\section{Improvement of specific energy} absorption of composite tubular absorbers using various stitching pattern designs

\section{Rabiee, Ali}

Springer

Rabiee A, Ghasemnejad H. (2020) Improvement of specific energy absorption of composite tubular absorbers using various stitching pattern designs. Applied Composite Materials, Volume 27, Issue 6, December 2020, pp. 717-738 https://doi.org/10.1007/s10443-020-09842-2

Downloaded from Cranfield Library Services E-Repository 